\title{
MOTIVASI DAN PRESTASI BELAJAR MATEMATIKA SISWA PADA PEMBELAJARAN MODEL KOOPERATIF TIPE THINK PAIR SHARE
}

\author{
Aprisa V. Liunome ${ }^{1}$, Farida Daniel ${ }^{2 *}$, Prida N. L. Taneo ${ }^{3}$ \\ ${ }_{1,2,3}$ Program studi pendidikan Matematika STKIP Soe \\ *faridanie146@gmail.com
}

Dikirim: 09 Oktober 2019. Disetujui:28 Januari 2020. Dipublikasikan: 31 Januari 2020

\begin{abstract}
ABSTRAK
Motivasi merupakan salah satu faktor pendukung dalam mencapai prestasi belajar matematika. Motivasi sebagai penggerak melalui usaha, dapat berpengaruh positif terhadap prestasi belajar matematika siswa. Hasil observasi di SMK Teknik Anugerah Soe menunjukkan bahwa prestasi belajar matematika siswa masih rendah. Penyebabnya yaitu siswa lebih senang bekerja mandiri, kurang berpartisipasi dalam aktivitas belajar serta kurangnya kreativitas guru dalam mendesain pembelajaran. Salah satu alternatif untuk mengatasi permasalahan di atas adalah dengan pembelajaran model kooperatif tipe Think Pair Share (TPS). Tujuan penelitian ini adalah 1) menghasilkan kajian tentang pengaruh motivasi terhadap prestasi belajar matematika siswa pada pembelajaran model kooperatif tipe TPS; 2) meningkatkan prestasi belajar matematika siswa pada pembelajaran model kooperatif tipe TPS. Penelitian ini menggunakan metode kuantitatif model pre-eksperimental dengan rancangan one group pretest-posttest design melibatkan satu kelas penelitian dengan teknik purposive sampling. Instrumen yang digunakan sebagai alat pengumpulan data adalah tes berupa soal uraian, angket dan observasi. Teknik analisis data dalam penelitian ini menggunakan uji regresi, uji t-sampel berpasangan dan skor gain. Hasil analisis menunjukkan bahwa 1) terdapat pengaruh motivasi terhadap prestasi belajar matematika pada pembelajaran model kooperatif tipe TPS; 2)terdapat peningkatan prestasi belajar matematika siswa pada pembelajaran model kooperatif tipe TPS yang berada pada kategori tinggi dengan rata-rata skor gain 0,76 . Kata kunci: motivasi, prestasi belajar matematika, Think Pair Share (TPS).
\end{abstract}

\begin{abstract}
Motivation is one of the supporting factors in achieving student's achievement in learning mathematics. Motivation is the motor of effort which can influence positively on the student's achievement. The observation result in SMK Teknik Anugerah Soe showed that the student's achievement in learning mathematics was still low. The reasons were they tent to learn individually, less in participation in learning activities and the minim of teacher's creativity in designing the teaching-learning process. One of the alternatives to cope with the problem above is by using cooperative teaching model type TPS. The purpose of this research is 1) to produce a review about the influence of motivation on the student's achievement in learning mathematics on cooperative teaching model type TPS; 2) to improve the student's achievement in learning mathematics on cooperative teaching model type TPS. This research used a quantitative method pre-experimental model using one group pretest-posttest design which involved a class of research with a purposive sampling technique. The instruments used in collecting the data were essay tests, questionnaires, and observation. The analysis techniques used in this research were a regressive test, paired sample t-test, and gain score. The analysis results show that 1) there is a motivation influence on the student's achievement in learning mathematics using cooperative teaching model type TPS; 2) there is an enhancement on the student's achievement in learning mathematics using cooperative teaching model type TPS which in on the highest category with average is 0,76 gain score.
\end{abstract}

Keywords:motivation, student's mathematic achievement, Think Pair Share (TPS). 


\section{Pendahuluan}

Pendidikan nasional bertujuan untuk membentuk manusia susila yang cakap,warga negara yang demokratis serta bertanggungjawab tentang kesejahteraan masyarakat dan tanah air lewat pembelajaran pada suatu lembaga pendidikan (UU nomor 20 tahun 2003). Aktivitas belajar matematika di sekolah merupakan salah satu faktor pendukung dalam mencapai tujuan pendidikan yang memberikan nilai positif dalam mencerdaskan kehidupan bangsa. Pembelajaran matematika menekankan hubungan antara pengalaman belajar siswa sebelumnya dengan konsep yang akan diajarkan dan juga berfokus pada upaya guru dalam memotivasi dan memfasilitasi siswa untuk belajar bukan pada apa yang dipelajari.

Kegiatan belajar yang bervariasi serta kreativitas guru dalam mendesain pembelajaran merupakan tujuan utama dalam mencapai prestasi belajar matematika (Sumiati dan Asra, 2007:11).Hasil Programme for International Student Assessment (PISA) tahun 2015 Indonesia berada pada urutan 63 dari 70 negara untuk bidang matematika menunjukkan bahwa prestasi belajar matematika siswa di Indonesia masih rendah.Prestasi belajar matematika yang rendah juga terjadi di wilayah Nusa Tenggara Timur (NTT) berdasarkan rata-rata nilai Ujian Nasional (UN) mata pelajaran matematika tiga tahun terakhir tingkat SMA dan SMK yang disajikan pada Tabel 1.

Tabel 1. Nilai Rata-rata UN Mata Pelajaran Matematika Provinsi NTT

\begin{tabular}{ccccc}
\hline \multirow{3}{*}{ Tahun } & \multicolumn{4}{c}{ Nilai Rata-rata } \\
& SPA & SMA & Bahasa & SMK \\
\hline 2015 & 36,54 & 33,01 & 35,60 & 30,87 \\
2016 & 32,07 & 30,68 & 38,01 & 35,74 \\
2017 & 30,72 & 30,98 & 34,30 & 32,46 \\
\hline
\end{tabular}

(Sumber:https://hasilun.puspendik.kemdikbud.go.id)

Tinggi rendahnya prestasi yang diperoleh tidak hanya disebabkan oleh faktor intelegensi siswa tetapi salah satu faktor yang mempengaruhi prestasi yaitu motivasi belajar (Warti, 2016).Motivasi belajar merupakan keseluruhan daya penggerak di dalam diri siswa yang menimbulkan, menjamin kelangsungan dan memberikan arah kegiatan belajar, sehingga dapat mencapai tujuan yang diharapkan (Sutikno, 2007:94). Motivasi memiliki pengaruh positif terhadap prestasi belajar matematika.Semakin tepat motivasi yang diberikan, akan berpengaruh pada peningkatan hasil belajar siswa (Sardiman, 2010:75). Motivasi sebagai faktor dalam menentukan prestasi belajar matematika yang dicapai siswa sebab tanpa motivasi maka siswa tidak akan tertarik untuk belajar serta tidak memperoleh kepuasaan dari belajar matematika (Indriani, 2016). Rendahnya motivasi akan berakibat pada prestasi belajar matematika siswa yang kurang memuaskan (Arvyaty, Maonde dan Noho, 2016).

Hasil observasi menunjukkan bahwa prestasi belajar matematika siswa masih rendah. Rendahnya prestasi belajar matematika dilihat dari nilai rata-rata UN mata pelajaran matematika tahun 2015-2017 yang disajikan pada Tabel 2. Hasil observasi juga menunjukkan bahwa motivasi belajar matematika siswa masih rendah yang dilihat dari sikap siswa selama mengikuti pembelajaran yaitu kebanyakan siswa kurang serius dalam mengerjakan tugas matematika yang diberikan, cepat menyerah dalam mengerjakan soal yang sulit, kurang berminat untuk memecahkan masalah yang diberikan serta lebih senang memilih untuk menyalin pekerjaan dari temannya. 
Tabel 2. Nilai Rata-rata UN Mata Pelajaran Matematika

\begin{tabular}{cc} 
& SMK Teknik Anugerah Soe \\
\hline Tahun & Nilai Rata-rata \\
\hline 2015 & 21,3 \\
2016 & 20,5 \\
2017 & 30,4 \\
\hline
\end{tabular}

Pembelajaran yang kurang bervariasi juga berpengaruh terhadap prestasi belajar matematika siswa. Selama pembelajaran berlangsung setelah guru menyampaikan materi siswa diberikan soal-soal untuk dikerjakan, kebanyakan siswa memilih mengerjakan soal secara mandiri tanpa memanfaatkan waktu untuk berdiskusi dengan teman lain dankurang berperan aktif ketika guru meminta untuk mengerjakan soal di depan kelas. Kegiatan belajar mengajar yang bervariasi dan kreativitas guru dalam menentukan model pembelajaran dapat mempengaruhi aktivitas siswa dalam mencapai prestasi belajar matematika yang baik. Faktor pendukung untuk mencapai prestasi yaitu melalui ketepatan dalam memilih model pembelajaran sehingga guru dituntut untuk mempunyai kreativitas dalam merancang pembelajaran. Salah satu alternatif untuk mengatasi masalah di atas adalah dengan pembelajaran model kooperatif tipe Think Pair Share (TPS).

Model kooperatif tipe TPS merupakan salah satu pembelajaran yang efektif untuk membuat variasi suasana pola diskusi kelas dengan memberikan waktu lebih banyak kepada siswa untuk mengkonstruksi dan mendiskusikan ide-ide secara bebas serta membagikan informasi kepada teman lain (Lailatul, 2015).Pembelajaran kooperatif tipe TPS membantu siswa sehingga terciptanya interaksi dalam menyelesaikan masalah-masalah matematika (Putri, Yerizon dan Nilawasti, 2014). Hal ini didukung oleh hasil penelitian Widati (2016) yang menyimpulkan bahwa model kooperatif tipe TPS dapat meningkatkan motivasi dan prestasi belajar matematika siswa.Langkah-langkah pembelajaran model TPS disajikan pada Tabel 3.

Tabel 3.Langkah-langkah Pembelajaran Model TPS

Tahapan Deskripsi Kegiatan

\begin{tabular}{ll}
\hline Think (berpikir) & Guru mengajukan pertanyaan atau isu yang berhubungan dengan \\
& pelajaran, kemudian siswa diminta untuk memikirkan pertanyaan atau \\
& isu tersebut secara mandiri untuk beberapa saat. \\
Pair (berpasangan) & Guru meminta siswa agar berpasangan dengan siswa yang lain untuk \\
& mendiskusikan apa yang telah mereka pikirkan pada tahap pertama. \\
& Interaksi pada tahap ini diharapkan dapat berbagi jawaban jika telah \\
& diajukan suatu pertanyaan, atau berbagai ide jika suatu persoalan \\
& khusus telah diidentifikasi. \\
Guru meminta kepada pasangan untuk berbagi dengan seluruh kelas \\
tentang apa yang telah mereka diskusikan. Hal ini cukup efektif jika \\
dilakukan dengan cara bergiliran antara pasangan demi pasangan, dan \\
dilanjutkan sampai sekitar seperempat pasangan telah mendapatkan \\
kesempatan untuk melaporkan.
\end{tabular}

(Majid, 2013:191) 
Tujuan penelitian ini adalah untuk menghasilkan kajian tentang: (1) Pengaruh motivasi terhadap prestasi belajarmatematika siswa pada pembelajaran model kooperatif tipe TPS; (2) peningkatan prestasi belajarmatematika siswa pada pembelajaran model kooperatif tipe TPS.

\section{Metode Penelitian}

Metode yang digunakan dalam penelitian ini adalah metode kuantitatif model preeksperimental dengan rancangan one group pretest-posttest design. Desain penelitian ini melibatkan satu kelas.Sebelum pembelajaran dilakukan prestest untuk mengetahui kemampuan awal siswa.Setelah itu dilakukan pembelajaran model kooperatif tipe TPS kemudian diberikan posttest untuk mengetahui kemampuan akhir siswa.Populasi pada penelitian ini adalah seluruh siswa SMK Teknik Anugerah Soe kelasX yang terdiri dari dua kelas yaitu kelas desain permodelan informatika bangunan (DPIB), teknik komputer dan jaringan (TKJ) dan sampelnya adalah kelas X DPIB yangditentukan dengan teknik purposive sampling.

Teknik pengumpulan data pada penelitian ini adalah menggunakan tes, observasi dan angket.Tes yang digunakan berupa soal uraian untuk memperoleh data prestasi belajar matematika siswa.Tes dilakukan sebanyak dua kali yaitu pretest dan posttest.Observasi dilakukan untuk mengamati secara cermat aktivitas siswa yang mencerminkan motivasi belajar matematika selama proses pembelajaran berlangsung serta mencatat peristiwa yang terjadi sebagai data pendukung dalam menganalisis pelaksanaan dan hasil penelitian.Angket yang digunakan adalah angket motivasi belajar matematika siswa yang diisi oleh siswa setelah pembelajaran kooperatif tipe TPS.Analisis data dilakukan pada data prestasi dan motivasi belajar matematika siswa. Teknik analisis data berupa uji normalitas, uji pengaruh, uji beda, uji t-sampel berpasangan dan skor gain normalisasi.

\section{Hasil Penelitian dan Pembahasan}

Prestasi belajar matematika siswa dapat dilihat dari deskripsi statistik hasil tes yang disajikan pada Tabel 4.

Tabel 4. Deskripsi Statistik Hasil Tes

\begin{tabular}{lcc}
\hline \multicolumn{1}{c}{ Statistik } & Pretest & Posttest \\
\hline Nilai tertinggi & 69 & 97 \\
Nilai terendah & 15 & 67 \\
Rata-rata & 46,75 & 86,44 \\
Simpangan baku & 14,79 & 10,75 \\
\hline
\end{tabular}

Tabel 4 menunjukkan bahwa terdapat peningkatan prestasi belajar matematika siswa dengan hasil perolehan skor pretest yang lebih rendah dari skor posttest. Simpangan baku data posttest yang lebih kecil dari data pretest menunjukkan bahwa kemampuan setiap siswa setelah pembelajaran model kooperatif tipe TPS cenderung lebih homogen dibanding sebelum pembelajaran model kooperatif tipe TPS.

Analisis dengan regresi linear sederhana diperoleh nilai sig $=0,02<\alpha=0,05$ menunjukkan bahwa terdapat hubungan linear antara motivasi belajar dan prestasi belajar matematika. Nilai $R$ square yang diperoleh adalah $0,502=50,2 \%$ yang berarti bahwa motivasi belajar berpengaruh terhadap prestasi belajar matematika sebesar 50,2\% sedangkan 49,8\% 
dipengaruhi oleh variabel lain yang tidak diamati pada penelitian ini. Persamaan regresi yang diperolehadalah $\hat{Y}=-15,483+1,376 X$, semakin besar motivasi belajar yang diberikan semakin besar pula prestasi belajar matematika siswa. Hasil analisis ini menunjukkan bahwa terdapat pengaruh motivasi terhadap prestasi belajar matematika pada model pembelajaran kooperatif tipe TPS.Penelitian Indriani (2016) juga menyatakan hal serupa yaituterdapat pengaruh motivasi terhadap prestasi belajar matematika.

Hasil observasi dan analisis angket motivasi belajar menunjukkan bahwa kerjasama dengan teman lain pada pembelajaran model kooperatif tipe TPS dapat membantu siswa dalam menyelesaikan masalah matematika. Siswa menjadi lebih tekun, optimis, tidak mudah mengalah dengan teman lain dalam berkompetisi dan ulet dalam menghadapi kesulitan.

Motivasi berpengaruh terhadap prestasi belajar matematika karena adanya faktor intrinsik dan ekstrinsik yang mendorong siswa untuk melakukan aktivitas belajar matematika. Faktor intrinsik berasal dari dalam diri individu berupa ketekunan, pemahaman dan usaha dalam menyelesaikan masalah matematika sehingga membantu siswa dalam mencapai prestasi belajar matematika yang lebih baik. Faktor ekstrinsik berasal dari luar individu yang meliputi lingkungan belajar, teman-teman dan guru.

Analisis dengan paired sampel t-test diperoleh $t_{\text {hitung }}=-10,450<t_{\text {tabel }}=-1,753$. Hasil analisis ini menunjukkan adanya peningkatan prestasi belajar matematika siswa pada pembelajaran model kooperatif tipe TPS sebesar 0,76 dengan kriteria tinggi. Hasil penelitan Lailatul (2015) juga menyatakan bahwa terdapat peningkatan prestasi belajar matematika pada pembelajaran model kooperatif tipe TPS.Peningkatan prestasi belajar matematikaterjadi karena pembelajaran model kooperatif tipe TPS menekankan pada partisipasi siswa sehingga siswa lebih aktif dalam menyelesaikan masalah yang diberikan.Hal ini sejalan dengan penelitian Widati (2016) yang menyatakan bahwa terdapat peningkatan prestasi belajar matematika pada pembelajaran model kooperatif tipe TPS yang disebabkan karena model pembelajaran ini memberikan kesempatan kepada siswa untuk mengkonstruksi ide, sehingga siswa yang dapat memecahkan soal yang diberikan.

Peningkatan prestasi belajar matematika disebabkan karena pembelajaran dengan model kooperatif tipe TPS dimulai dengan menyajikan permasalahan kepada siswa sehingga siswa termotivasi untuk belajar, dimana siswa yang menemukan sendiri penyelesaian dari masalah yang diberikan, lewat tahapan berpikir (think), berpasangan (pair) dan berbagi (share) (Majid, 2013:191).Think (berpikir),pada tahap ini siswa diberikan kesempatan untuk berpikir tentang masalah yang diberikan pada Lembar Kerja Siswa(LKS) secara mandiri agar siswa dapat memahami masalah yang diberikan; tahap pair (berpasangan),siswa bersama dengan temannya saling berbagi pendapat untuk menyelesaikan soal yang telah dikerjakan secara mandiri untuk mengambil suatu kesimpulan; tahap share (berbagi), hasil pembahasan yang telah diperoleh dibagikan kepada kelompok lain melalui presentasi di depan kelas.

Pembelajaran dengan model kooperatif tipe TPS membantu siswa untuk mengkonstruksi ide atau gagasan, mendiskusikan serta membagikan informasi kepada teman lain. Model kooperatif tipe TPS merupakan salah satu tipe pembelajaran kooperatif dengan prosedur yang ditetapkan secara eksplisit, untuk memberi waktu lebih banyak kepada siswa sehingga mampu berpikir, menjawab dan saling membantu satu sama lain (Majid, 2013:191).

Teori Piaget menekankan aktivitas individu dalam pembentukan pengetahuan lewat proses asimilasi, skemata, equilibiration dan accommodation (Yamin, 2012:60). Pembelajaran model kooperatif tipe TPS memadukan potensi siswa memecahkan masalah secara individu, 
berpasangan kemudian berbagi jawaban dengan anggota kelompok lainnya melalui presentasi.Hal ini memberikan kesempatan lebih banyak bagi siswa untuk berdiskusi dengan kelompoknya dan interaksi antar siswa juga lebih mudah (Putri, Yerizon dan Nilawasti, 2014).

Peningkatan prestasi belajar matematika siswa disebabkan karena pembelajaran dengan model kooperatif tipe TPS memberikan waktu lebih banyak kepada siswa untuk mengkostruksi ide, mendiskusikan secara berkelompok serta membagikan informasi yang telah diperoleh kepada teman lainnya. Hal serupa juga dinyatakan oleh Arvyaty, Maonde dan Noho (2016) bahwa peningkatan prestasi belajar matematika disebabkan karena pembelajaran model kooperatif tipe TPS dapat memotivasi siswa untuk bisa berpikir sendiri dengan materi yang disampaikan guru, memberikan kesempatan kepada siswa agar dapat berbagi dengan pasangannya, dapat mengutarakan hasil pemikiran mereka masing-masing dan memperoleh kesempatan untuk berbagi informasi kepada kelompok lain lewat presentasi.

\section{Simpulan dan Saran}

Simpulan

Berdasarkan hasil analisis data dapat disimpulkan bahwa 1) terdapat pengaruh motivasi terhadap prestasi belajar matematika siswa pada pembelajaran model kooperatif tipe TPS;2) terdapat peningkatan prestasi belajar matematika siswa dengan pembelajaran model kooperatif tipe TPS yang berada pada kategori tinggi.

Saran

Saran dari hasil penelitian ini adalah dalam pembelajaran model kooperatif tipe TPS siswa harus lebih percaya diri saat berdiskusi dengan pasangannya maupun saat berbagi dengan teman sekelasnya agar hasil yang diperoleh selama pembelajaran maksimal.

\section{Daftar Pustaka}

Arvyaty, Maonde, F. dan Noho, N. (2016). Pengaruh Motivasi Berprestasi terhadap Prestasi Belajar Matematika Siswa SMA Negeri dan SMA Swasta di Kota Kendari. Jurnal Pendidikan Matematika, 7(1), (pp.26-42). Kendari : Universitas Halu Oleo.

Indriani, A. (2016). Pengaruh Motivasi Belajar Siswa Kelas V terhadap Prestasi Belajar Matematika Matematika di SDN Kecamatan Kunduran Kabupaten Blora.Jurnal Ilmiah Pendidikan Matematika, 4(2), (pp.134-140). Madiun: Universitas PGRI Madiun.

Lailatul, S. (2015). Strategi Pembelajaran TPS (Think Pair Share) terhadap Motivasi Belajar Siswa.Jurnal Pendidikan Matematika, 3(1), (pp.61-68). Sidoarjo: STKIP PGRI Sidoarjo.

Majid, A. (2013).Strategi Pembelajaran. Bandung: PT Remaja Rosdakarya.

Putri, S. Y., Yerizon dan Nilawasti. (2014).Pengaruh Penerapan Model Pembelajaran Tipe Think Pair Share Terhadap Aktivitas dan Hasil Belajar Matematika Siswa Kelas VII SMP N 31 Padang. Jurnal Pendidikan Matematika, 3(1), (pp.41-45). Padang: UNP.

Sardiman.(2010). Interaksi dan Motivasi Belajar Mengajar. Jakarta: PT Rajawali Persada.

Sumiati dan Asra. (2007). Metode Pembelajaran. Bandung: CV Wacana Prima.

Sutikno, P. (2007). Metode Pembelajaran. Bandung: PT Refika Aditama.

Undang-Undang Republik Indonesia Nomor 20 Tahun 2003 Tentang Sistem Pendidikan Nasional. Jakarta.

Warti, E. (2016). Pengaruh Motivasi Belajar Siswa Kelas V Terhadap Hasil Belajar Matematika Siswa di SD Angkasa 10 Halim Perdana Kusuma Jakarta Timur. Jurnal Mosharafa, 5(2),(pp.177-185). Garut: IPI Garut. 
Widati, R. S. (2016). Penerapan Model Kooperatif Tipe Think Pair Share untuk Meningkatkan Prestasi Belajar Matematika Siswa Kelas I SDN I Josari Kec. Jetis Kab. Ponorogo. Jurnal Aristo, 4( 2), (pp.129-143). Ponorogo: Universitas Muhammadiyah Ponorogo.

Winataputra, U. S., Delfi, R., Pannen, P. dan Mustafa, D. (2014). Teori Belajar dan Pembelajaran. Jakarta: Universitas Terbuka.

Yamin, M. (2012). Paradigma Baru Pembelajaran. Jambi: Madani. 